\title{
Cadmium removal from aqueous solution by jackfruit seed bio-adsorbent
}

\author{
Nirupama Prasad ${ }^{1} \cdot$ Pranav Kumar $^{1} \cdot$ Dan Bahadur Pal ${ }^{1}$
}

Received: 19 February 2020 / Accepted: 15 April 2020 / Published online: 5 May 2020

(c) Springer Nature Switzerland AG 2020

\begin{abstract}
In this present study, jackfruit bio-adsorbent was synthesized and utilized as cost effective for the removal of cadmium from aqueous solution. Jackfruit bio-adsorbent was characterized using emission scanning electron microscope, energy dispersive X-ray spectroscopy, thermal gravimetric analysis, Fourier transform infrared spectroscopy, X-ray diffractive spectroscopy and inductively coupled plasma optical emissions spectrometer techniques. Effects of different parameters such as solution $\mathrm{pH}$, dosage of adsorbent, stirring speed and concentration of cadmium removal were evaluated and optimized. The maximum adsorption was achieved at speed of $120 \mathrm{rpm}, \mathrm{pH} 7.6,60 \mathrm{mg}$ adsorbent dose and contact time for $1 \mathrm{~h}$, the optimum adsorption efficiency of about $97.12 \%$ was observed even at lower adsorbent dosing of $60 \mathrm{mg}$. Activation energy of the jackfruit bio-adsorbent was also being evaluated, which was observed $130.69 \mathrm{~kJ} / \mathrm{mol}$ using FWO method which attributed to a chemisorptions adsorption process.
\end{abstract}

Keywords Bio-adsorbent · Thermal kinetics · Jackfruit seeds · Cadmium removal

\section{Introduction}

Wastewater containing heavy metals are mainly released from the industries like electroplating, paint, cement, mining, dyeing etc. Chemical industries effluents mostly contain heavy metals such as cadmium, iron, copper, chromium, arsenic, lead etc. and its compounds. These heavy metals may bring long-term threat to environment and human being, when released in water [23]. Cadmium (Cd) is considered to be one of the most hazardous contaminants present in waste water. These contaminants generally enter into the water bodies through various industrial and agricultural practices and can adversely reacts with the ecosystem even at very low quantities $[6-9,11,21$, 41]. Therefore before discharging the wastewater in the river and lake from these industries, effluent treatment is required. After treatment the maximum limit of cadmium is equals $0.003 \mathrm{mg} / \mathrm{L}$. There are different methodologies available for wastewater treatment like coagulation, electro-coagulation, flocculation, filtration, membrane separation; adsorption reverses osmosis, precipitation and bioremediation [16, 17, 18, 29, 37]. There are different methodologies available for wastewater treatment like coagulation, electro-coagulation, flocculation, filtration, membrane separation;adsorption reverses osmosis, precipitation and bioremediation [16, 29, 37]. Among them, adsorption is one of the most common and commercially adopted techniques because of its good efficiency with simple procedure and low operational cost $[4,12,20]$. In the adsorption technology, an adsorbent is used in the powder form in the wastewater on which heavy metals adsorbs on the surface and settle down and clean water is on the top of the container $[6-9,41]$. In the recent years, scientific community has been used a number of materials as an adsorbent including stones, shells, and various fruit seeds, sewage slags and biomass $[1,6,9,38]$. The presence

Dan Bahadur Pal, danbahadur.chem@gmail.com | 'Department of Chemical Engineering, Birla Institute of Technology, Mesra, Ranchi, Jharkhand 835215 , India. 
of this waste can cause undesirable effects on the health of the human body and other organisms primarily through interactions with enzymes in their cells $[3,16,29,37]$. Due to the high cost of commercial carbons, researchers are searching for the material which is cheap, affordable and easily accessible to produce activated carbon. In this respect, agricultural and industrial wastes $[6-9,41]$ can be those appropriate raw materials to produce appropriate activated carbon for the removal of heavy metals from the waste water $[3,24,30]$.

The present study is focused on the synthesis, characterization, thermal degradation kinetic of biomass to used material like jackfruit bio-adsorbent and its application in cadmium removal from aqueous solution.

\section{Materials and method}

\subsection{Experimental setup}

The self assembled experimental setup to perform in batch adsorption process [33,34]. The experimental setup consist a magnetic stirrer of capacity 0 to $500 \mathrm{rpm}$ with least count $5 \mathrm{rpm}$ and $100 \mathrm{ml}$ beaker consists of cadmium contained water with different concentration range varying from 0.5 to $2.5 \mathrm{ppm}$ has been subjected to purify in presence of bio-adsorbent. The experiments have been performed with different adsorbent dosing. The experiments have been performed for $50 \mathrm{~min}$ to optimize adsorbent dosing, rpm of magnetic stirrer, $\mathrm{pH}$ of solution and cadmium concentration of the solution. The removal of cadmium from the polluted water was studied in $10 \mathrm{~min}$ interval up to $2 \mathrm{~h}$.

\subsection{Preparation of bio-adsorbent}

Jackfruit seeds (JFS) was collected from the fruit market near the campus of the Birla Institute of Technology, Mesra, Ranchi, Jharkhand, India. The seed was washed with tap water followed by distilled water to remove dust particles and other impurities from the surface. After washing, seeds were dried in an air oven for $48 \mathrm{~h}$ at $60^{\circ} \mathrm{C}$ for removing moisture. Figure 1 shows the dried seeds which is ready for crushing and milling to make it powder form. The powder has been kept in sheave shaker and all equal size particles have been distinguished. The higher size particles have been again crushed to find minimum particle size. After getting all equal size particles the powder sample has been send for different types of characterization and again calcined it at $400{ }^{\circ} \mathrm{C}$ for $3 \mathrm{~h} \mathrm{[16]}$.

\subsection{Adsorbent characterization}

FESEM-EDX was recorded on Sigma-300 with EDX (Ametek) Field Emission Scanning Electron Microscope instrument. An accelerating voltage of $15 \mathrm{kV}$ and a magnification of $1000 \mathrm{X}$ were used. Thermo gravimetric analysis (TGA) and Differential Thermal Analysis (DTA) performed on a Shimadzu (Japan;

Fig. 1 Flow chart of jackfruit seeds based bio-adsorbent

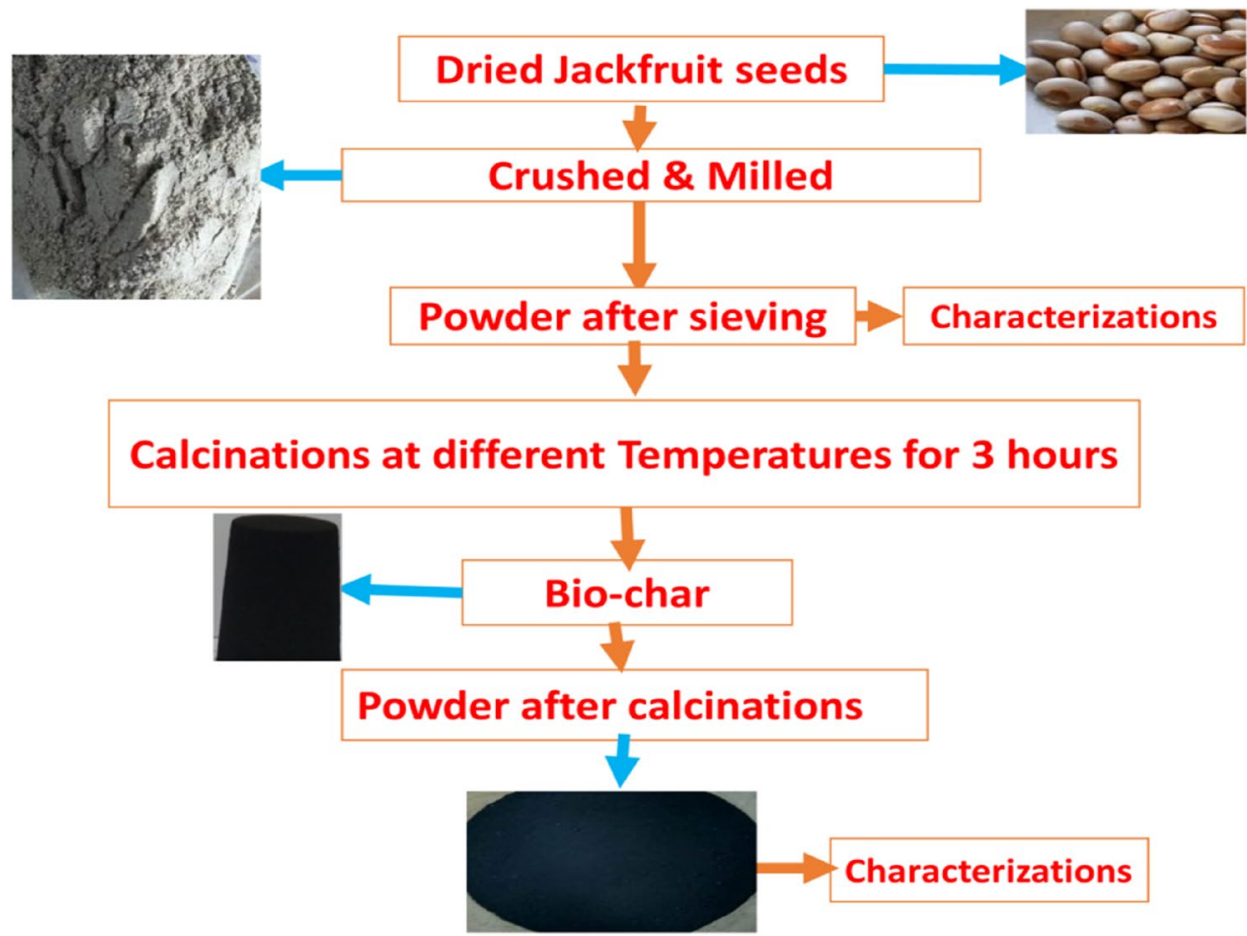

SN Applied Sciences 
DTG-60) in Nitrogen environment, at a different heating rate of $10-50{ }^{\circ} \mathrm{C} / \mathrm{min}$. FTIR spectrum of the prepared adsorbent was recorded in the range of $400-4000 \mathrm{~cm}^{-1}$ using Shimadzu (Corporation, Japan; IR-Prestige 21). The elemental analysis by Inductively Coupled Plasma Optical Emissions spectrometer in Perkin Elmer, Optical 2100DV ICP-OES (USA) with spectral range of $160-900 \mathrm{~nm}$, spectral resolution of $0.009 \mathrm{~nm}$ at $200 \mathrm{~nm}$ and speed of $20-25$ elements in less than $5 \mathrm{~min}$.

\subsection{Experimental design}

All the experiments have been designed with the help of design-expert 6.0.8. Response surface methodology has been used to optimize the process parameters for maximizing the percentage pollutant removal from aqueous solution. Within this methodology, a four factor and five level central composite design (CCD) has been implemented to study the combined effect of all the four parameters [pollutant concentration (A), mixing speed (B), $\mathrm{pH}(\mathrm{C})$ and adsorbent dose (D)] on the percentage removal of pollutant from aqueous solution [35]. The range and levels of all the four selected parameters studied in the experiments have been presented in Table 1.

\subsection{Thermal kinetic}

The common rate equation governs in all kinetic studies can be generally written as follows:

$\frac{\mathrm{d} \alpha}{\mathrm{dt}}=k(T) f(\alpha)$

where $\frac{d \alpha}{d t}$ is the rate of conversion at a constant temperature, $f(a)$ is the reaction model which describes the changes in the physical or chemical properties, $\mathrm{k}$ is the rate constant, dependent on temperature T.

The conversion rate a (using TGA records) is defined as:

$\alpha=\frac{w_{o}-w_{t}}{w_{o}-w_{f}}$

Table 1 The range and levels of selected parameters studied in the experiments

\begin{tabular}{lll}
\hline Variables & \multicolumn{2}{l}{ Range and level } \\
\cline { 3 - 3 } & Low & High \\
\hline Pollutant concentration (A) (ppm) & 0.5 & 2.5 \\
mixing speed (B) (rpm) & 110 & 150 \\
$\mathrm{pH}(\mathrm{C})$ & 3 & 11 \\
Catalyst dose (D) (mg) & 20 & 100 \\
\hline
\end{tabular}

where $w_{o}, w_{t}$ and $w_{f}$ are the initial mass of the sample at $t=0$, mass of the sample at time $t$ and mass of the sample at final degradation respectively.

According to the Arrhenius relationship, the rate constant is the function of temperature and can be written as follows:

$k(T)=\mathrm{k}_{0} \exp \left(\frac{-E}{R T}\right)$

where $\mathrm{k}_{\mathrm{o}}$ is the pre-exponential factor, $R$ is the gas constant $(8.314 \mathrm{~J} / \mathrm{K} \mathrm{mol})$, and $E$ is the activation energy $(\mathrm{kJ} /$ mol).

Using Eqs. (1) and (3) following equation can be derived:

$\frac{\mathrm{d} \alpha}{\mathrm{dt}}=\mathrm{k}_{0} \exp \left(\frac{-E}{R T}\right) f(\alpha)$

Equation (4) describes the relationship between the conversion rate, rate constant and temperature which is used for recording the experimental data. To conduct kinetic study in TGA one of the ways is to use a heating rate, $=d T / d t$. Equation (4) can be written as follows:

$\frac{\mathrm{d} \alpha}{\mathrm{dT}}=\frac{\mathrm{k}_{0}}{\beta} \exp \left(\frac{-E}{R T}\right) f(\alpha)$

Equation (5) is most basic equations used for kinetic study of thermal degradation.

$E$, activation energy can be estimated using various models. Generally used methods are Kissinger, Friedman, Flynn and Wall, Coats-Redfern, and Flynn-Wall-Ozawa (F-W-O) $[15,19,25]$. In this study, we used $\mathrm{F}-\mathrm{W}-\mathrm{O}$ method which gives slope (-E/RT) from the line obtained by plotting log $\beta$ against $1 / T$ at fixed degree of conversion.

$\mathrm{F}-\mathrm{W}-\mathrm{O}$ fitting equation is given below [31]:

$\log f(\propto)=\log \left\{\frac{k_{0} E}{R}\right\}-\log \beta-2.315-0.4567 \frac{E}{R T}$

\section{Result and discussion}

\subsection{Field emission scanning electron microscopy (FESEM)}

The morphology of the jackfruit seed powder (JFSP) after calcination at $400{ }^{\circ} \mathrm{C}$ for $3 \mathrm{~h}$, they were subjected to Field Emission scanning electron microscopy (FESEM) analysis of three different magnifications shown in Fig. $2 a-c$ its diameter is around $3 \mu \mathrm{m}$ and spherical shape obtained in all magnifications $[6-9,41]$. 

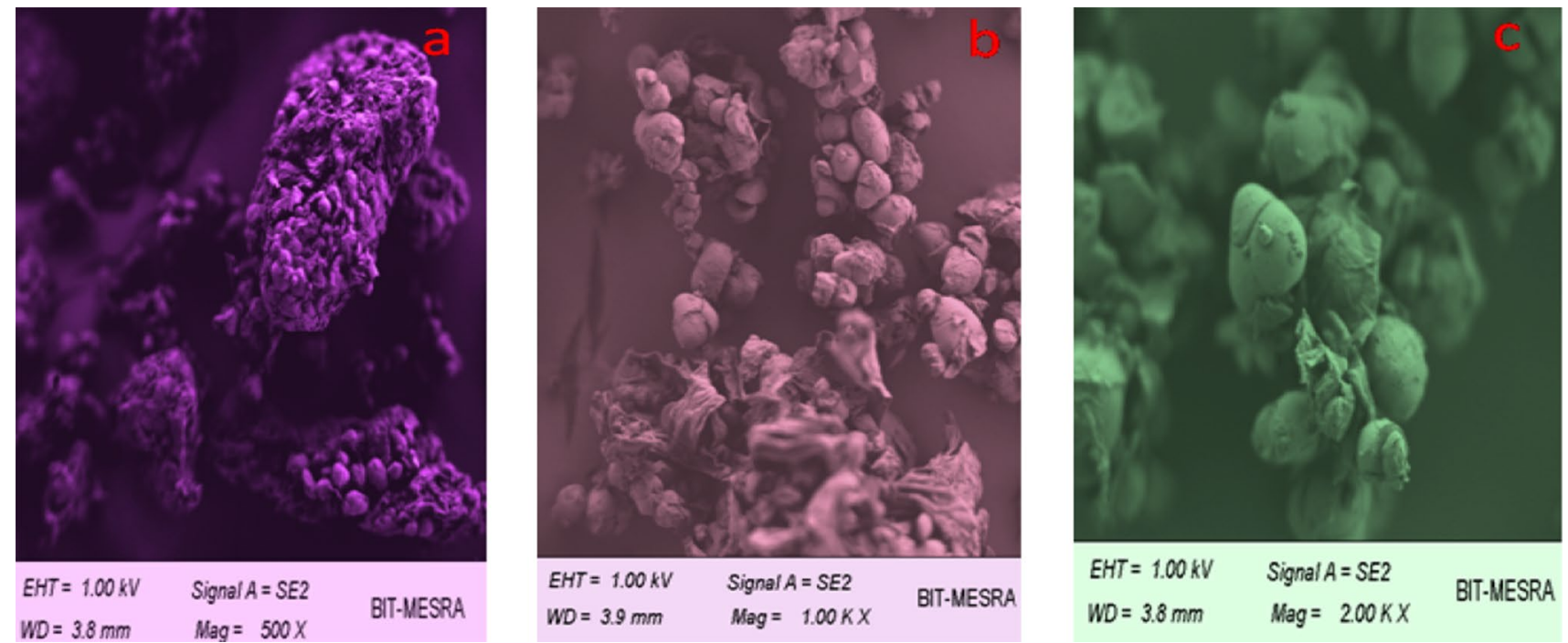

Fig. 2 FE-SEM images of jackfruit seeds calcined at calcined at $400^{\circ} \mathrm{C}$ for $3 \mathrm{~h}$

\subsection{Energy dispersive X-ray spectroscopy (EDX) and inductively coupled plasma optical emissions spectrometer (ICP-OES)}

Energy dispersive X-ray spectroscopy analysis was conducted to quantify the near surface amount of elements present in the bio-adsorbent. From Fig. 3, it can be seen that $71.23 \%$ oxides, $4.94 \%$ calcium, $2.5 \%$ calcium $1.5 \%$ manganese and rest are carbon present in the sample on weight percentage basis [39]. Inductively Coupled Plasma Optical Emissions spectrometer analysis of the JFSP before the calcination of sample the major composition are magnesium, iron, calcium, copper, zinc, manganese, nickel and cobalt etc. [6-9,41]. Theivasanthi also studied and shown

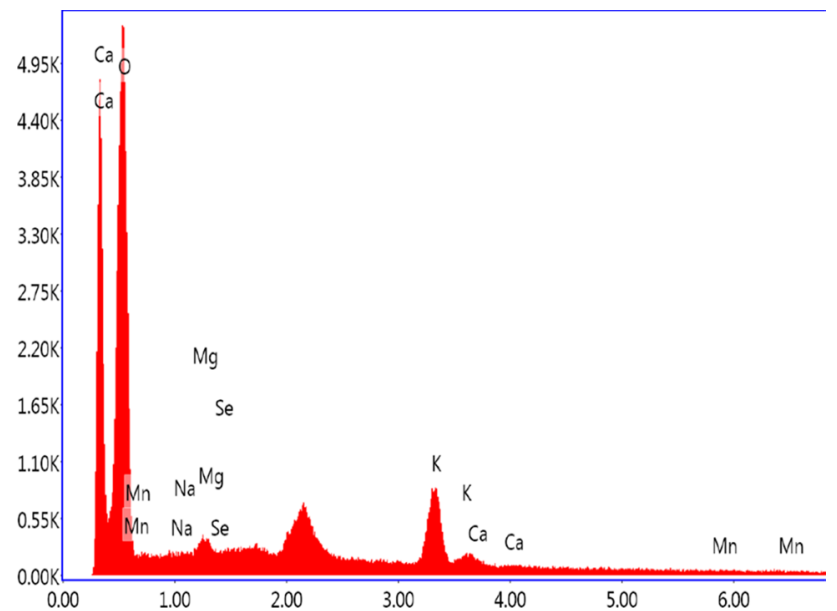

Fig. 3 EDX spectra of jackfruit seeds similar trace elements like carbon, oxygen, magnesium, aluminium, phosphorus, potassium, titanium, iron, nickel and molybdenum.

\subsection{Fourier transform infrared spectroscopy (FTIR) analysis}

The FTIR spectral analysis revealed several functional groups on the surface of biomass shown in Fig. 4. The absorption peak observed at wave-number $3279 \mathrm{~cm}^{-1}$ is associated with $\mathrm{O}-\mathrm{H}$ stretching vibration. The wave-numbers around $2927 \mathrm{~cm}^{-1}$ and $2364 \mathrm{~cm}^{-1}$ are corresponding to the $\mathrm{C}-\mathrm{H}$ aliphatic stretching vibration. The peak displayed at $1643 \mathrm{~cm}^{-1}$ is attributing to the stretching band of the carboxyl double bond from carboxyl functional group. The peak around $1150 \mathrm{~cm}^{-1}$ is indicative of $P=O$ stretching present in phosphate group. It has been observed by the $[6-9,22,41]$. [22] the carboxyl groups present in jackfruit bio-adsorbent plays a significant role in the cation cadmium removal. The peak displayed at wave number $1007 \mathrm{~cm}^{-1}$ is assigned to the $\mathrm{O}-\mathrm{H}$ stretching of primary alcohol group. The peak at $929 \mathrm{~cm}^{-1}$ shows the $C-C$ links in the bio-carbon. The presence of polar groups on the biocarbon surface is likely to provide the considerable cation exchange capacity to the absorbent [2].

\subsection{Thermo-gravimetric analysis (TGA)}

The micrograph of TGA and DTA were used to study the thermal degradation behaviour of JFSP, as shown in Fig. 5. The DTA plot of JFSP shows three major endothermic peaks which indicated decomposition occurs in three main processes. The initial weight loss of $-10 \%$ in the

SN Applied Sciences 
Fig. 4 FTIR spectra of jackfruit seeds

Fig. 5 TG-DTA thermograms of jackfruit seeds
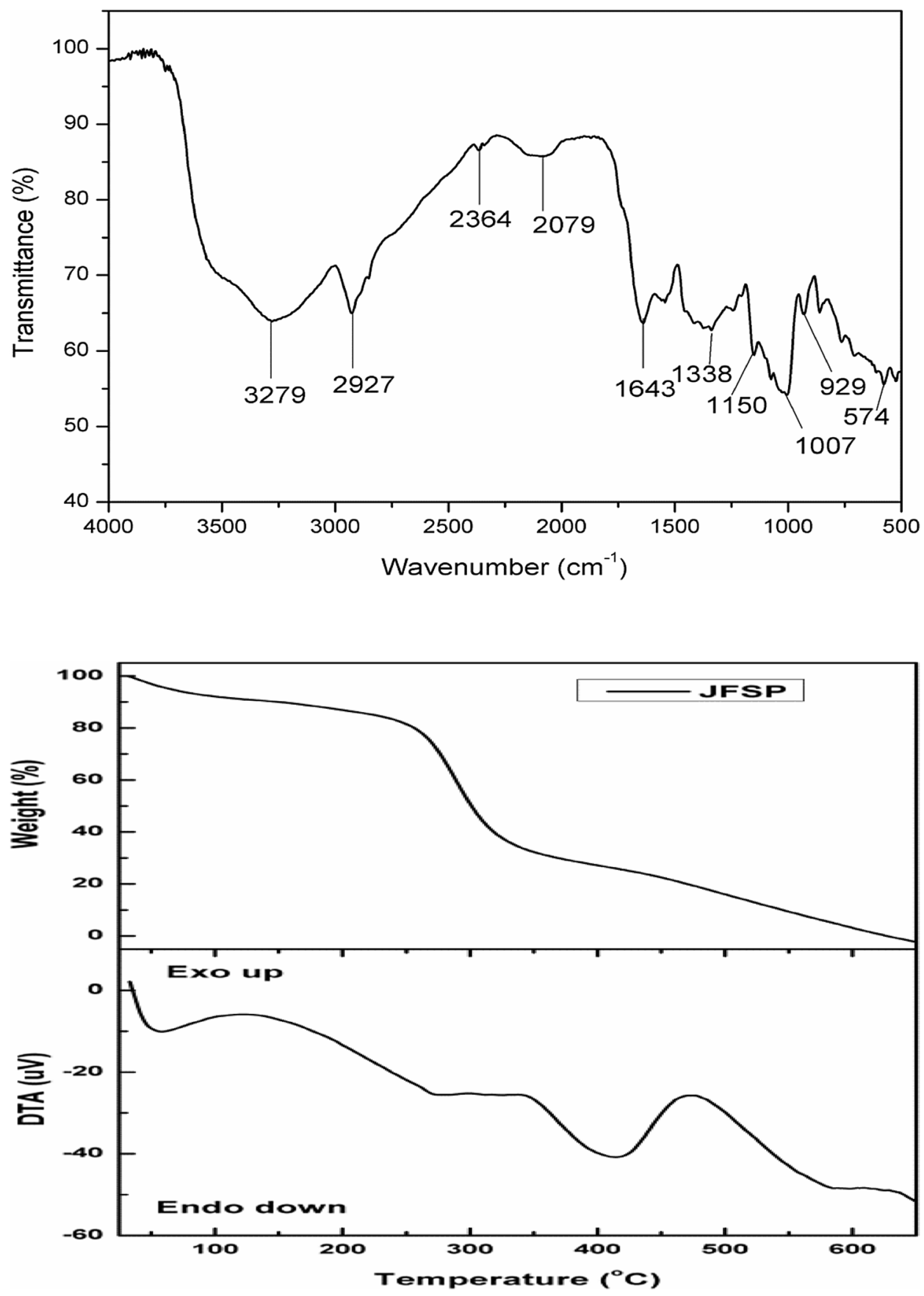

temperature range of $30-150{ }^{\circ} \mathrm{C}$, mainly corresponds to the evaporation of physically absorbed aqueous solution. DTA curve also shows first sharp endothermic peak at $59^{\circ} \mathrm{C}$ with change in enthalpy of $-1.4 \mathrm{~kJ} / \mathrm{g}$. TG curve revealed that above $150^{\circ} \mathrm{C}$, thermal stability is gradually decreasing and decomposition of the jackfruit bio-adsorbent occurs with the complete decomposition at $626^{\circ} \mathrm{C}$. The second stage decomposition process occurs in the temperature range of $150-332{ }^{\circ} \mathrm{C}$ (weight loss $64 \%$ ), showing second endothermic peak at $152{ }^{\circ} \mathrm{C}$ with change in enthalpy of $-1.67 \mathrm{~kJ} / \mathrm{g}[6-9,41]$. This result is attributed to the thermal depolymerisation of hemicelluloses, pectins, the cleavage of glycosidic linkage of cellulose and some parts of lignin $[5,28,39]$. At a temperature range of $350-625^{\circ} \mathrm{C}$, third and last stage decomposition process occur at peak $415^{\circ} \mathrm{C}$ (change in enthalpy of $-3.02 \mathrm{~kJ} / \mathrm{g}$ ) showing weight loss of $\sim 99 \%$. This indicates the thermal degradation reactions taking place for the major constituent of the biomass that is cellulose and remaining lignin $[10,36]$. 


\subsection{Thermal kinetic}

Activation energy was estimated using TGA data at five different heating rates $\left(10-30^{\circ} \mathrm{C} / \mathrm{min}\right)$. The average activation energy was determined using isothermal FWO method from the thermal degradation conversion range of 0.1-0.9. Figure 6 shows the linear plot jackfruit bio-adsorbent at various conversion rates. At various thermal degradation conversion rates, Activation energy was estimated from the slope of the curves. Summary of the activation energy values with $R^{2}$ values are given in Table 2. From the result, it can be observed that the activation energy varies with the varying rate of conversion, indicating high degree of probability to present more than one step reaction. Higher activation values are observed in the middle con version rate (0.3-0.6) whereas lower activation energy values were observed for lower and higher conversion rate [6-9, 41]. Activation energy is the minimum amount of energy required to initiate a reaction. Activation energy is dependent on the pyrolysis reaction mechanism; higher value of

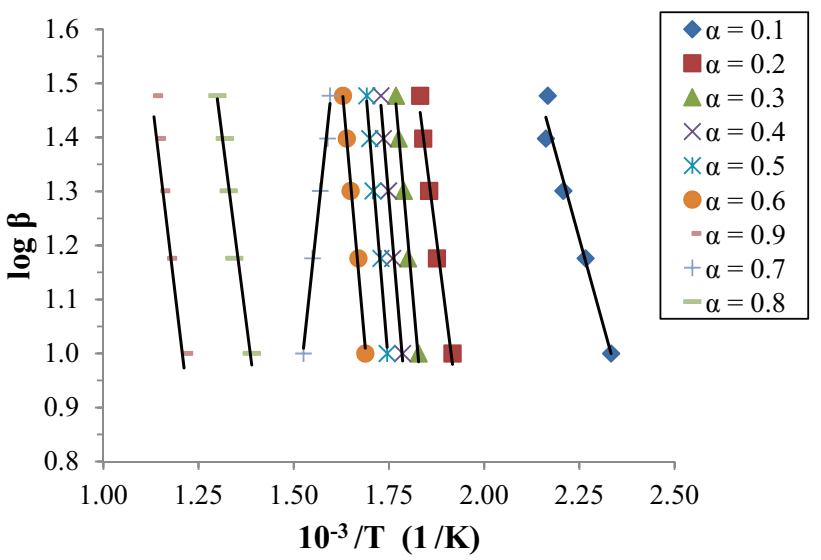

Fig. 6 Curves of fitting to kinetic model proposed by Flynn-WallOzawa ( $\mathrm{F}-\mathrm{W}-\mathrm{O}$ ) to various conversion percentages

Table 2 Kinetic parameters obtained from F-W-O method with fitted equation for Jackfruit (JF) power

\begin{tabular}{|c|c|c|c|}
\hline $\begin{array}{l}\text { Conversion } \\
\text { rate (a) }\end{array}$ & Equations & $\mathrm{R}^{2}$ & $\mathrm{E}_{,}(\mathrm{kJ} /$ mole $)$ \\
\hline 0.1 & $y=-2.5565 x+6.9645$ & 0.97 & 46.54 \\
\hline 0.2 & $y=-5.4866 x+11.498$ & 0.98 & 99.88 \\
\hline 0.3 & $y=-8.0076 x+15.621$ & 0.99 & 145.77 \\
\hline 0.4 & $y=-8.3145 x+15.835$ & 0.99 & 151.36 \\
\hline 0.5 & $y=-8.5099 x+15.862$ & 0.99 & 154.92 \\
\hline 0.6 & $y=-7.8898 x+14.329$ & 0.99 & 143.63 \\
\hline 0.7 & $y=6.5171 x-8.9333$ & 0.99 & 120.02 \\
\hline 0.8 & $y=-5.4511 x+8.5543$ & 0.97 & 99.23 \\
\hline 0.9 & $y=-5.8823 x+8.1026$ & 0.97 & 107.08 \\
\hline
\end{tabular}

activation energy indicates slower reaction [25]. This variation in activation energy is probably observed due to the mechanism involving the thermal decomposition of the jackfruit bio-adsorbent matter is different $[18,21,18,29$, 40]. This could be explained by the TGA curve (Fig. 6). The thermal degradation temperature for $a=0.1-0.2$ is around $270^{\circ} \mathrm{C}$ and for $\mathrm{a}=0.5$ is around $312^{\circ} \mathrm{C}$. This is the part of the TGA curve where maximum thermal degradation takes place. The observed activation energy is $130.69 \mathrm{~kJ} / \mathrm{mol}$, which corresponds to the degradation of hemi-cellulose, cellulose and lignin [31]. According to [26], value of the activation energy indicates about the type of adsorption taking place, which is physical or chemical adsorption. For the physical adsorption processes activation values usually found in the range of $0-40 \mathrm{~kJ} / \mathrm{mol}$, while higher activation energies values i.e. in the range of $40-800 \mathrm{~kJ} / \mathrm{mol}$ indicates chemical adsorption processes $[6-9,39]$.

\subsection{Statistical analysis}

The results were obtained in terms of percentage removal of cadmium from the aqeous solution for all the individual experiments and then statistical analysis has been performed by using the Design-Expert. The optimisation study has been conducted with Design-Expert software to maximize the percentage removal and is presented in the following subsections. According to the design discussed in the earlier section, a total number of 30 experiments have been conducted. For the further study these values have been fed to the Design-Expert software, which helps to predict the model (quadratic equation). This equation relates the independent variables $(A, B, C$ and $D)$ and dependent variable (\% removal) as shown in Eq. (7).

$$
\begin{aligned}
Y= & +33.61+13.22 A+0.39 B+3.67 C \\
& +0.322 D-2.54 A^{2}-0.0001 B^{2}-0.158 C^{2}-1.27 D^{2} \\
& -0.062 A * B+0.187 A * C+0.0187 A * D \\
& -0.015 B * C-0.0015 B * D+4.68 C * D
\end{aligned}
$$

where $Y$ is the cooling rate and $A, B, C$ and $D$ are Pollutant concentration, mixing speed, $\mathrm{pH}$ and bio-adsorbent dose respectively. The value of correlation coefficient $R^{2}$, used to check the model validity, is found to be 0.92 .

\subsection{Effects of $\mathrm{pH}$}

The effect of $\mathrm{pH}$ was studied from a range of 3-11 under the precise conditions at an optimum contact time of $1 \mathrm{~h}$ with $25 \mathrm{mg}$ of the adsorbents used for $100 \mathrm{~mL}$ of aqueous solution, and at a room temperature and it was observed that with increase in the $\mathrm{pH}(3-8)$ of the aqueous solution, 


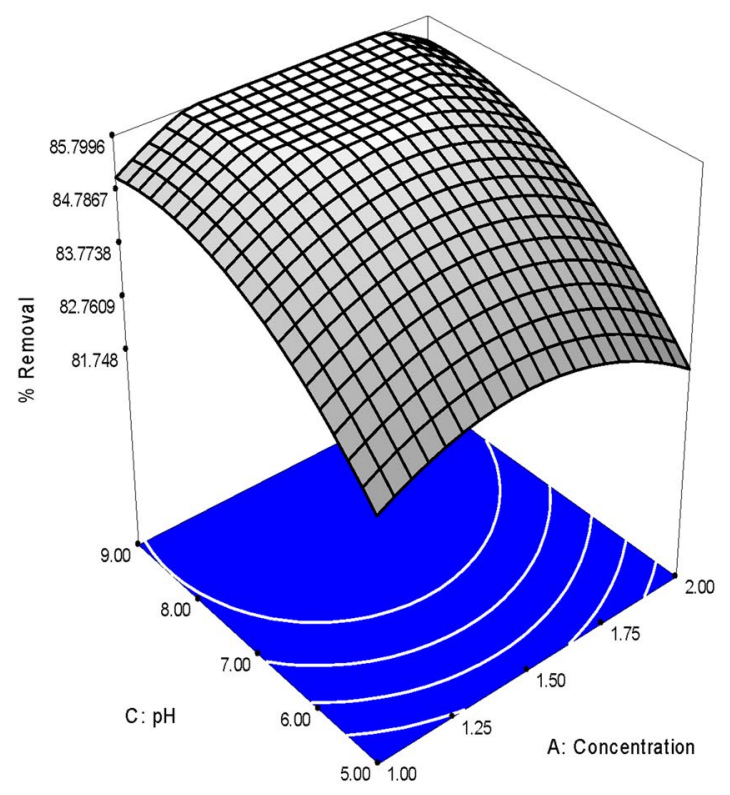

Fig. 7 Effects of $\mathrm{pH}$ on cadmium removal

the percentage removal of cadmium ion increased up to the $\mathrm{pH} 7-8$ as shown in Fig. 7. At pH 7.5, maximum removal was obtained for cadmium ions, with $96.7 \%$. The increase in percentage removal of the cadmium ions may be explained by the fact that at higher $\mathrm{pH}$ the functional groups in the adsorbent surface were deprotonated and become negatively charged and while at lower $\mathrm{pH}$, adsorption rate decreases and this is because at lower pHs, there is competition between $\mathrm{H}+$ ions and cadmium ions $[6-9,26,41]$.

\subsection{Effects of concentration and steering speed}

The effect of initial concentration $0.5-2.5$ ppm was investigated at ambient temperature with regular intervals of $10 \mathrm{~min}$ to $2 \mathrm{~h}$ for the adsorbent dosage of $20-100 \mathrm{mg}$ and steering speed ranges $110-150$ rounds per minutes. From the obtained result (Fig. 8), no significant change has been observed for the percentage removal of cadmium ions with the increase in initial concentration of cadmium ions. This is probably because of the removal of cadmium ions by forming complex with bio-adsorbent $[6-9,27,41]$. This observation indicates that the adsorption of cadmium by jackfruit bio-adsorbent is mostly depends upon the

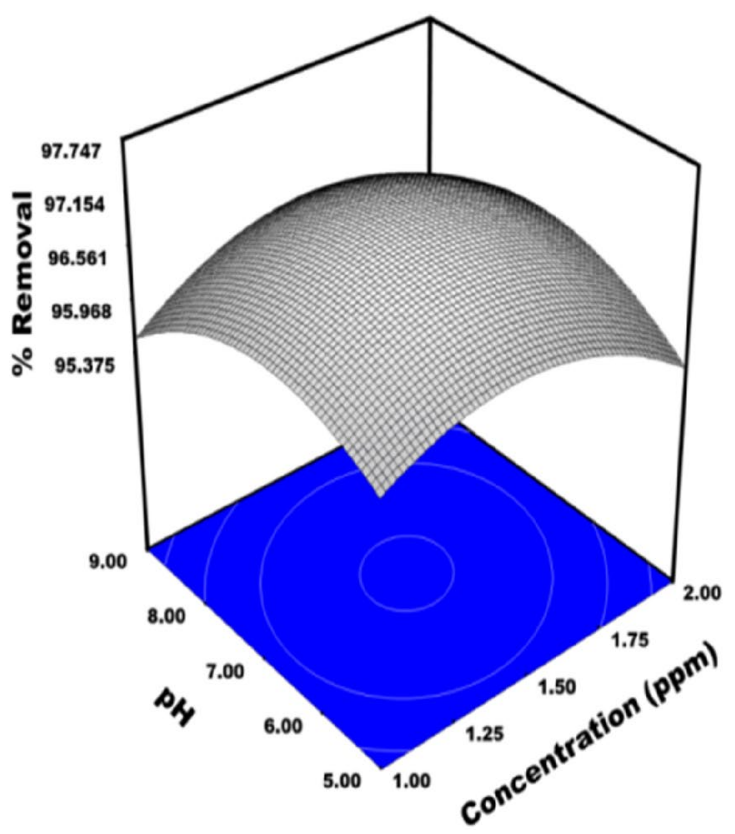

number of active sites present which can be able make complex with the metal ion. Similar result has also been reported by Mohammad et al. [27], which shows saturation point at the same time interval for different initial conc. This corresponds to the availability of more vacant biding sites for cadmium adsorption during initial contact times [32].

\subsection{Effects of adsorbents dosing}

For the present study, effect of variation in dosing (25-100 mg) was analyzed under the specified conditions at amibent condition. Sample was collected for the analysis of percentage removal of cadimium in the regular interval of $10 \mathrm{~min}$ for the period $2 \mathrm{~h}$. From the experimetal results shown in Fig. 9, it can be clearly seen that the percentage removal of cadmium ions has been increased with the increase in adsorbent dosing. Maximum adsorption efficiency of about $97.12 \%$ was observed even at lower adsorbent dosing of $60 \mathrm{mg}$. Further increase in adsorbent dosing has not been shown any significant effect on the sorption $[6-9,41]$. This is probably because of the availability of more binding sites at higher dose of bio adsorbents [13]. 

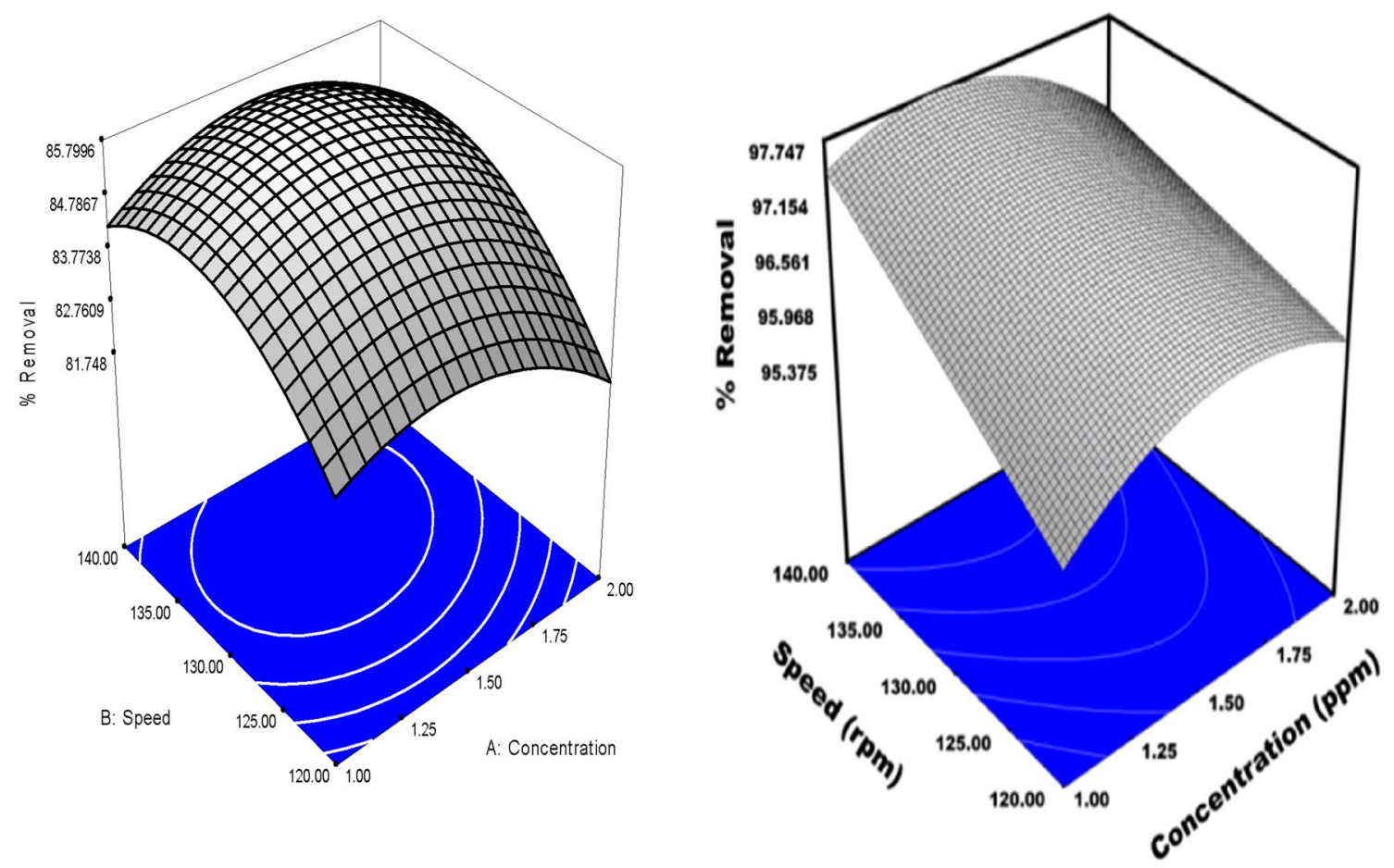

Fig. 8 Effects of Concentration and Steering Speed on cadmium removal
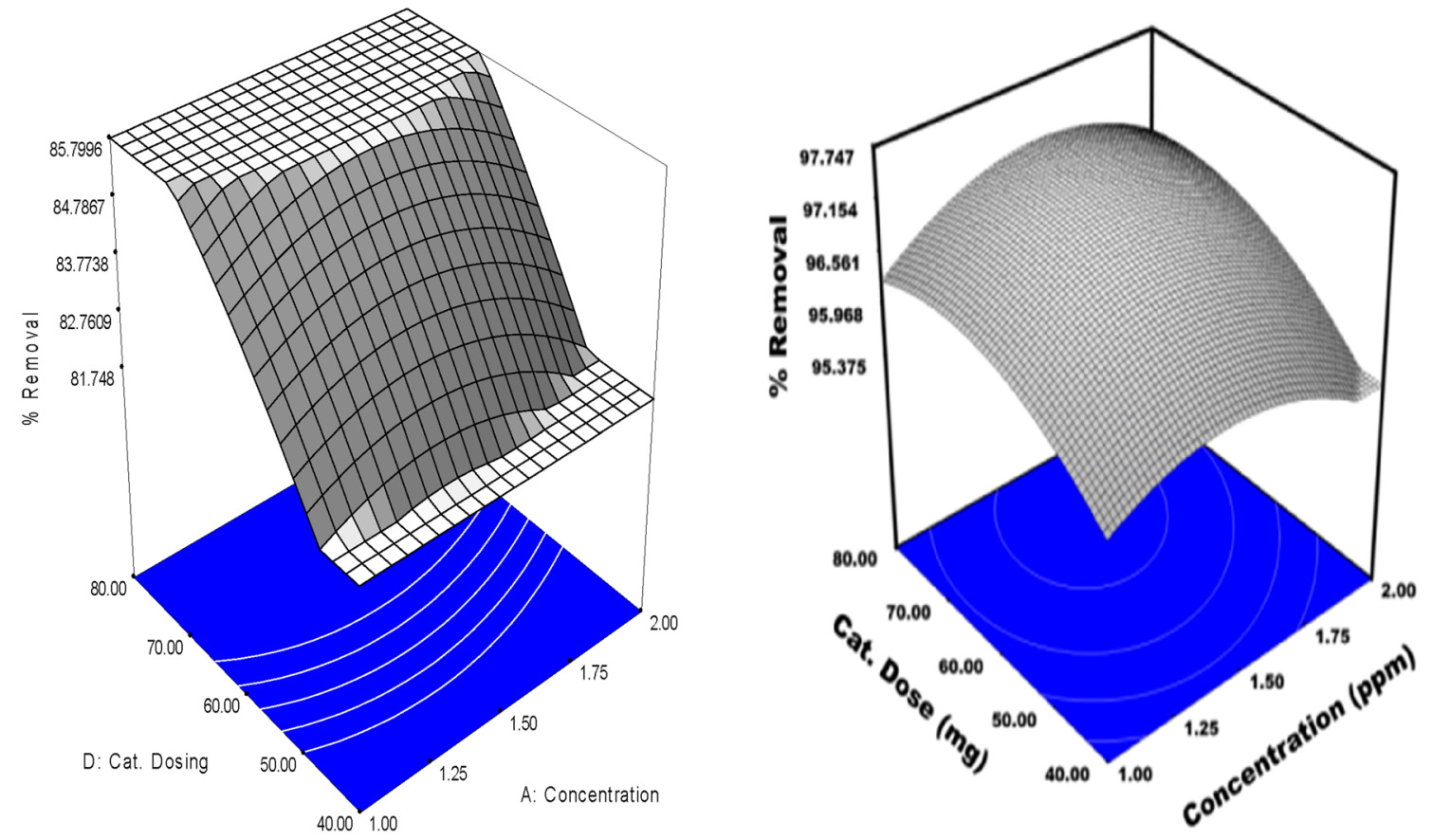

Fig. 9 Effects of dosing of adsorbent on cadmium removal 


\section{Conclusion}

Successfully prepared jackfruit bio-adsorbent for the removal of Cadmium from the aqueous solution. FTIR analysis shows the presence of carboxyl group in jackfruit bio-adsorbent which plays a significant role in the metal removal and the presence of polar groups on the bio-absorbent surface is likely to provide the considerable cation exchange capacity to the absorbent. TGA analysis shows maximum thermal decomposition in the range of $150-380^{\circ} \mathrm{C}$. Activation energy was observed $130.69 \mathrm{~kJ} / \mathrm{mol}$ using FWO method which attributed to a chemi-sorption adsorption process. Jackfruit bio-adsorbent was used successfully to remove cadmium ions from aqueous solution $\sim 97 \%$ in $1 \mathrm{~h}$ at $120 \mathrm{rpm}$ speed and $\mathrm{pH}$ 7.6. This study shows a new trend for using waste materials as a jackfruit bio-adsorbent for the benefit of pollution control.

Acknowledgements The authors acknowledge CIF-BIT, Mesra, Ranchi, Jharkhand and National Project Implementation Unit (NPIU) (TEQIPIII), New Delhi Govt. of India for the financial support.

\section{Compliance with ethical standards}

Conflict of interest There are no conflicts of interest between authors.

Ethical standard There is no involvement of human or animal cell in this work. All the co-authors have seen the final manuscript and agreed with the submission to the journal. The manuscript has not been published elsewhere. The article is not consideration under any other journal in full or in part. No data or figures have been fabricated or manipulated. The finding agencies (NPIU/AICTE New Delhi, India) have been duly acknowledged. All the authors agree to transfer copy right to SN Applied Science's.

\section{References}

1. Abbas K, Znad H, Awual M (2018) A ligand anchored conjugate adsorbent for effective mercury(II) detection and removal from aqueous media. Chem Eng J 334:432-443

2. Abdel-Ghani NT, Hegazy AK, El-Chaghaby GA (2009) Typhadomingensis leaf powder for decontamination of aluminium, iron, zinc and lead: biosorption kinetics and equilibrium modeling. Int J Environ Sci Technol 6:243

3. Adebisi GA, Chowdhury ZZ, Alaba PA (2017) Equilibrium, kinetic, and thermodynamic studies of lead ion and zinc ion adsorption from aqueous solution onto activated carbon prepared from palm oil mill effluent. J Clean Prod 148:958

4. Alslaibi TM, Abustan I, Ahmad MA, Foul AA (2013) Cadmium removal from aqueous solution using microwaved olive stone activated carbon. J Environ Chem Eng 1:589

5. Arbelaiz A, Fernandez B, Ramos JA, Mondragon I (2006) Thermal and crystallization studies of short flax fibre reinforced polypropylene matrix composites: effect of treatments. Thermochim Acta 440:111
6. Awual MdR, Hasan MdM (2019) A ligand based innovative composite material for selective lead (II) capturing from wastewater. J Mol Liq 294:111679

7. Awual MdR (2020) Optimization of an innovative composited material for effective monitoring and removal of cobalt(II) from wastewater. J Mol Liquid 298:112035

8. Awual MdR et al (2014) pH dependent Cu (II) and Pd (II) ions detection and removal from aqueous media by an efficient mesoporous adsorbent. Chem Eng J 236:100-109

9. Awual MdR, Hasan MdM, Znad H (2015) Organic-inorganic based nano-conjugate adsorbent for selective palladium (II) detection, separation and recovery. Chem Eng J 259:611-619

10. Benitez-Guerrero M, Lopez-Beceiro J, Sanchez-Jimenez PE, Pascual-Cosp J (2014) Comparison of thermal behavior of natural and hot-washed sisal fibers based on their main components: cellulose, xylan and lignin. TG-FTIR analysis of volatile products. Thermochim Acta 581:70

11. Bhanjana G, Dilbaghi N, Singhal NK, Kim KH, Kumar S (2017) Copper oxide nanoblades as novel adsorbent material for cadmium removal. Ceram Int 43:6075

12. Demirbas A (2008) Heavy metal adsorption onto agro-based waste materials: a review. J Hazard Mater 157:220

13. Devi V, Selvaraj M, Selvam P, Kumar AA, Sankar S, Dinakaran K (2017) Preparation and characterization of CNSR functionalized $\mathrm{Fe}_{3} \mathrm{O}_{4}$ magnetic nanoparticles: an efficient adsorbent for the removal of cadmium ion from water. J Environ Chem Eng 5:4539

14. Esvandi Z (2019) Physicochemical behavior of penaeuse semisulcatuse chitin for $\mathrm{Pb}$ and $\mathrm{Cd}$ removal from aqueous environment. J Polym Environ 27(2):263-274

15. Flynn JH, Wall LA (1966) General treatment of the thermogravimetry of polymers. J Res Natl Bureau Stand Sect A Phys Chem 70:487

16. Foroutan $\mathrm{R}$ (2020) Calcined alluvium of agricultural streams as a recyclable and cleaning tool for cationic dye removal from aqueous media. Environ Technol Innov 17:100530

17. Foroutan $\mathrm{R}$ (2019) Characteristics and performance of $\mathrm{Cd}, \mathrm{Ni}$, and $\mathrm{Pb}$ bio-adsorption using Callinectes sapidus biomass: real wastewater treatment. Environ Sci Pollut Res 26(7):6336-6347

18. Foroutan R, Zareipour R, Mohammadi R (2018) Fast adsorption of chromium $(\mathrm{VI})$ ions from synthetic sewage using bentonite and bentonite/bio-coal composite: a comparative study. Mater Res Express 6(2):025508

19. Gogoi M, Konwar K, Bhuyan N, Borah RC, Kalita AC, Nath HP, Saikia N (2018) Assessments of pyrolysis kinetics and mechanisms of biomass residues using thermogravimetry. Bioresour Technol Rep 4:40

20. Gupta VK, Ali I, Saleh TA, Nayak A, Agarwal S (2012) Chemical treatment technologies for waste-water recycling-an overview. RSC Adv 2:6380

21. Hashemi Z, Sharfiifard H, Lashanizadegan A (2018) Grape stalks biomass as raw material for activated carbon production: synthesis, characterization and adsorption ability. Mater Res Express 5:660

22. Kim N, Park M, Park D (2015) A new efficient forest biowaste as biosorbent for removal of cationic heavy metals. Bioresour Technol 175:629

23. Kumar S, Bhanjana G, Jangra K, Dilbaghi N, Umar A (2014) Utilization of carbon nanotubes for the removal of rhodamine $B$ dye from aqueous solutions. J Nanosci Nanotechnol 14:4331

24. Liew RK, Azwar E, Yek PNY, Lim XY, Cheng CK, Ng JH, Jusoh A, Lam WH, Ibrahim MD, Ma NL, Lam SS (2018) Microwave pyrolysis with $\mathrm{KOH} / \mathrm{NaOH}$ mixture activation: a new approach to produce micro-mesoporous activated carbon for textile dye adsorption. Bioresour Technol 266:1 
25. Mishra RK, Mohanty K (2018) Pyrolysis kinetics and thermal behavior of waste sawdust biomass using thermogravimetric analysis. Bioresour Technol 251:63

26. Mohamed MA (2013) Removal of uranium (VI) from aqueous solution using low cost and eco-friendly adsorbents. J Chem Eng Process Technol 4:169

27. Mohammad HD, Samira T, Ahmad P, Mostafa K, Ahmad Z, Zoha $\mathrm{H}$, Mahmood Y (2018) Adsorptive removal of noxious cadmium from aqueous solutions using poly urea-formaldehyde: a novel polymer adsorbent. Methods X 5:1148

28. Monteiro SN, Calado V, Rodriguez RJS, Margem FM (2012) Hermogravimetric stability of polymer composites reinforced with less common lignocellulosic fibers-An overview. J Mater Res Technol 1(2):117-126

29. Naeimi $\mathrm{B}$ et al (2018) $\mathrm{Pb}(\mathrm{II})$ and $\mathrm{Cd}(\mathrm{II})$ removal from aqueous solution, shipyard wastewater, and landfill leachate by modified Rhizopus oryzae biomass. Mater Res Express 5(4):045501

30. Norouzi S, Heidari M, Alipour V, Rahmanian O, Fazlzadeh M, Mohammadi-Moghadam F, Nourmoradi H, Goudarzi B, Dindarloo K (2018) Preparation, characterization and $\mathrm{Cr}(\mathrm{VI})$ adsorption evaluation of $\mathrm{NaOH}$-activated carbon produced from Date Press Cake; an agro-industrial waste. Bioresour Technol 258:48-56

31. Oza S, Ning H, Ferguson I, Lu N (2014) Effect of surface treatment on thermal stability of the hemp-PLA composites: correlation of activation energy with thermal degradation. Compos B Eng 67:227

32. Pandey S, Tiwari S (2015) Facile approach to synthesize chitosan based composite-characterization and cadmium(II) ion adsorption studies. Carbohyd Polym 134:646

33. Pal DB, Giri DD, Singh P, Pal S, Mishra PK (2017) Arsenic removal from synthetic waste water by $\mathrm{CuO}$ nano-flakes synthesized by aqueous precipitation method. Desal Wastewater Treat 62:355
34. Pal DB, Lavania R, Srivastava P, Singh P, Madhav S, Mishra PK (2018) Photo-catalytic degradation of methyl tertiary butyl ether from wastewater using $\mathrm{CuO} / \mathrm{CeO}_{2}$ composite nanofiber catalyst. J Environ Chem Eng 6:2577-2587

35. Park D, Yun YS, Park JM (2010) The past, present, and future trends of biosorption. Biotechnol Bioprocess Eng 15:86

36. Prasad N, Agarwal VK, Sinha S (2018) Thermal degradation of coir fiber reinforced low-density polyethylene composites. Sci Eng Compos Mater 25:363

37. Shafiee $\mathrm{M}$ et al (2019) Application of oak powder/ $/ \mathrm{Fe}_{3} \mathrm{O}_{4}$ magnetic composite in toxic metals removal from aqueous solutions. Adv Powder Technol 30(3):544-554

38. Shahat $A$ et al (2018) Novel nano-conjugate materials for effective arsenic $(V)$ and phosphate capturing in aqueous media. Chem Eng J 331:54-63

39. Theivasanthi TGV, Palanivelu M, Alagar M (2011) Nano sized powder of jackfruit seed: spectroscopic and anti-microbial investigative approach. Nano Biomed Eng 3(4):215-221

40. Zadeh BS et al (2020) Removal of Cd (II) from aqueous solution using eucalyptus sawdust as a bio-adsorbent: kinetic and equilibrium studies. J Environ Treat Tech 8(1):112-118

41. Znad H et al (2018) Synthesis a novel multilamellar mesoporous $\mathrm{TiO}_{2} / \mathrm{ZSM}-5$ for photo-catalytic degradation of methyl orange dye in aqueous media. J Environ Chem Eng 6(1):218-227

Publisher's Note Springer Nature remains neutral with regard to jurisdictional claims in published maps and institutional affiliations. 